\title{
Effect of sevoflurane on systemic and cerebral circulation, cerebral autoregulation and $\mathrm{CO}_{2}$ reactivity
}

\author{
Marianna Juhász ${ }^{1}$, Levente Molnár ${ }^{1}$, Béla Fülesdi1 ${ }^{1,3^{*}} \mathbb{D}$, Tamás Végh ${ }^{1,3}$, Dénes Páll ${ }^{2}$ and Csilla Molnár ${ }^{1}$
}

\begin{abstract}
Background: Sevoflurane is one of the most frequently used inhaled anesthetics for general anesthesia. Previously it has been reported that at clinically used doses of sevoflurane, cerebral vasoreactivity is maintained. However, there are no data how sevoflurane influences systemic and cerebral circulation in parallel. The aim of our study was to assess systemic and cerebral hemodynamic changes as well as cerebral $\mathrm{CO}_{2}$-reactivity during sevoflurane anesthesia.
\end{abstract}

Methods: Twenty nine patients undergoing general anesthesia were enrolled. Anesthesia was maintained with 1 MAC sevoflurane in $40 \%$ oxygen. Ventilatory settings (respiratory rate and tidal volume) were adjusted to reach and maintain 40, 35 and $30 \mathrm{mmHg}_{\mathrm{EtCO}}$ for 5 min respectively. At the end of each period, transcranial Doppler and hemodynamic parameters using applanation tonometry were recorded.

Results: Systemic mean arterial pressure significantly decreased during anesthetic induction and remained unchanged during the entire study period. Central aortic and peripherial pulse pressure and augmentation index as markers of arterial stiffness significantly increased during the anesthetic induction and remained stable at the time points when target $\mathrm{CO}_{2}$ levels were reached. Both cerebral autoregulation and cerebral $\mathrm{CO}_{2}$-reactivity was maintained at 1 MAC sevoflurane.

Discussion: Cerebral autoregulation and $\mathrm{CO}_{2}$-reactivity is preserved at $1 \mathrm{MAC}$ sevoflurane. Cerebrovascular effects of anesthetic compounds have to be assessed together with systemic circulatory effects.

Trial registration: The study was registered at http://www.clinicaltrials.gov, identifier: NCT02054143, retrospectively registered. Date of registration: February 4, 2014.

Keywords: Sevoflurane, Cerebral blood flow, cerebral autoregulation, $\mathrm{CO}_{2}$-reactivity, applanation tonometry, Transcranial Doppler

\section{Background}

The most important vasoregulatory mechanisms determining brain circulation are cerebral autoregulation and cerebral vasoreactivity. Cerebral autoregulation is the inherent ability of the brain circulation to maintain constant cerebral blood flow during alterations of systemic blood pressure and cerebral perfusion pressure. Cerebral vasoreactivity is responsible for enabling to

\footnotetext{
*Correspondence: fulesdi@med.unideb.hu

'Faculty of Medicine, Department of Anesthesiology and Intensive Care,

University of Debrecen, Nagyerdei krt. 98, Debrecen, Hungary

${ }^{3}$ Hungarian Center, Outcomes Research Consortium, Cleveland, USA

Full list of author information is available at the end of the article
}

change the blood flow (either globally or locally) according to the metabolic needs of the brain tissue [1]. Ideally, anesthetic agents should not have any significant impact on cerebral autoregulation and cerebral vasoreactivity during general anesthesia, which is especially important in the neurosurgical practice. There are data indicating that volatile anesthetics may alter both autoregulation and cerebral vasoreactivity to carbon-dioxide [2-4] under general anesthesia. Inhalational agents are usually characterized by dose-dependent depressive effect on cerebral autoregulation, with the exception of sevoflurane [3]. Sevoflurane, the most widely used inhalational agent does not influence cerebral vasoreactivity at MAC levels 
between 0.3 and 1.5 in healthy individuals [5]. There are reports suggesting that the autoregulatory plateau is shortened under sevoflurane anesthesia with MAC 1, and the upper and lower limits of autoregulation were independent of the age of the patients [5].

During induction and maintenance of general anesthesia different systemic and cerebral effects of the anesthetic agents have to be taken into account to have a global view on the anesthetic's effect and for the interpretation of the results. Thus, in the present study we aimed to assess changes in cerebral circulation and peripheral systemic hemodynamic changes in parallel during induction and maintenance of anesthesia with sevoflurane and the effect of different hypocapnic levels.

Applanation tonometry, a new, non-invasive method has been recently reported to be accurate for non-invasive intraoperative assessment of systemic hemodynamic changes during general anesthesia [6]. In line with this, for our measurements we used parallel assessment of systemic and cerebral circulation with the combination of applanation tonometry and transcranial Doppler.

We aimed to answer the following study questions:

- What is the effect of anesthetic induction and reaching the steady state sevoflurane anesthesia on systemic hemodynamics and cerebral blood flow measurements?

- Is cerebral autoregulation maintained at normocapnic steady state 1 MAC sevoflurane anesthesia?

- What are the cerebral and systemic hemodynamic effects of induced hypocapnia at 1 MAC sevoflurane?

\section{Methods}

\section{Study population}

After approval from the local Ethics Committee (DEOEC RKEB/IKEB 3584-2012;), written informed consent was obtained from 35 ASA I-II patients scheduled for varicectomy and inguinal hernial repair surgery. The study was registered at http://www.clinicaltrials.gov, identifier: NCT02054143, retrospectively registered. Exclusion criteria were age $<18$ years or $>60$ years, severe cardiovascular disease, severe carotid artery stenosis, cerebrovascular disease, smoking, diabetes mellitus, renal disease, hyperlipidemia, left ventricular hypertrophy and severe alteration of the preoperative pulmonary function, characterized as FEV1 $<70 \%$ and FEV1/ FVC $\leq 70 \%$ of the predicted value.

\section{Devices and measurements}

For applanation tonometry SphygmoCor (AtCor Medical, Sydney, Australia) device was used. During applanation tonometry the sensor was placed on the patient's skin over the radial artery. This placement applies pressure on the radial artery and the pressure of the sensor flattens (i.e., 'applanates') the radial artery. Under optimal 'applanation conditions', the transmural pressure of the radial artery wall is zero and the intraluminal applanation tonometry can be recorded by the sensor. In the present study applanation tonometry parameters were recorded at the left radial artery. Using applanation tonometry we registered systolic and diastolic aortic pressure, aortic pulse pressure, peripherial pulse pressure, augmentation pressure, augmentation index normalized on actual heart rate (Alx@HR) and ejection duration. All measurements were performed by the same experienced operator (DP).

Transcranial Doppler (TCD) measurements were performed using Rimed Digilite transcranial Doppler sonography (Rimed Ltd., Israel). The temporal window was used for insonation of the middle cerebral artery at $45-55 \mathrm{~mm}$ depth, depending on the best signal. A fixed probe was used to register systolic, diastolic and mean blood flow velocities; pulsatility indices were calculated by the device.

\section{Study protocol}

Preoperative measurements were recorded one hour before anesthetic induction in supine position in quiet environment. Patients were then premedicated with 7.5 $\mathrm{mg}$ midazolam orally $60 \mathrm{~min}$ before entering the operating room. Anaesthesia was induced with a combination of $2 \mathrm{mg} \cdot \mathrm{kg}^{-1}$ propofol and $2 \mu \mathrm{g} . \mathrm{kg}^{-1}$ fentanyl. Intubation was facilitated by administration of $0.6 \mathrm{mg} \cdot \mathrm{kg}^{-1}$ rocuronium. Fentanyl and rocuronium were repeated as needed. Anesthesia was maintained with sevoflurane in $40 \%$ oxygen. The concentration of sevoflurane was titrated to a target Bispectral Index (BIS) between 40 and 60 (Covidien, Dublin, Ireland) and it was targeted at 1 MAC. Neuromuscular block was monitored with acceleromyography (TOF Watch SX, NV Organon, Oss, the Netherlands). Standard monitoring included fiveleads ECG, NIBP, core temperature at the tympanic membrane, and pulse oximetry. Normothermia was maintained with forced-air system (Bair Hugger 750, 3 M, Eden Prairie, MN, USA).

Patients were ventilated using volume-controlled square-wave flow pattern ventilation with $6-8 \mathrm{~mL} \cdot \mathrm{kg}^{-1}$ TV, $5 \mathrm{cmH}_{2} \mathrm{O}$ PEEP, $2 \mathrm{~L} \cdot \mathrm{min}^{-1}$ fresh gas flow and with a respiratory rate adjusted to reach and maintain 40 $\mathrm{mmHg} \mathrm{EtCO}_{2}$ (Draeger Primus anesthesia workstation, Draeger Lübeck, Germany).

After induction of general anaesthesia and intubation, lungs were ventilated in supine position for $20 \mathrm{~min}$ as described above. At this stage, hemodynamic, transcranial Doppler, applanation tonometry and ventilatory parameters were simultaneously recorded. 
In the second phase of the study minute ventilation (respiratory rate and tidal volume) was changed to reach and maintain $35 \mathrm{mmHg} \mathrm{EtCO}_{2}$. After $5 \mathrm{~min}$ stabilisation period all measurements were repeated.

At the next stage of measurement series ventilatory settings were again changed to reach and maintain 30 $\mathrm{mmHg} \mathrm{EtCO}_{2}$ After a 5 min stabilisation period, applanation tonometry and transcranial Doppler measurements were repeated. The flow chart of the study is summarized in Fig.1.

During each measurement pulse oxygen saturation $\left(\mathrm{SpO}_{2}\right)$, heart rate, systolic and diastolic blood pressure, bispectral index values, systolic, diastolic and mean blood flow velocities and pulsatility indices in the middle cerebral artery, systolic and diastolic aortic pressure, aortic pulse pressure, peripherial pulse pressure, augmentation pressure, Alx@HR, ejection duration and operation index were registered.

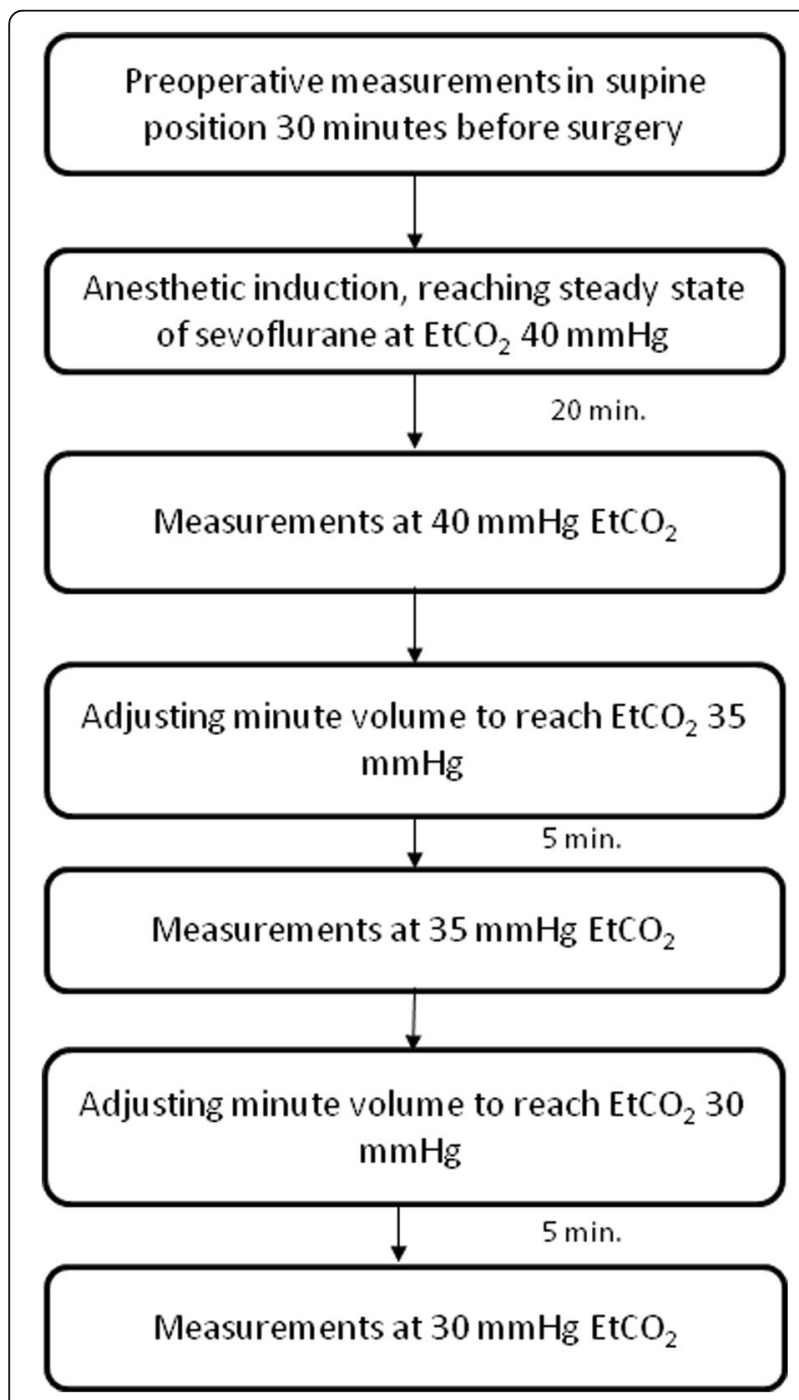

Fig. 1 Flow chart of the study
The entire study and its interpretation follows the CONSORT guidelines.

\section{Statistical methods}

Before starting the study, a power analysis was performed to calculate the necessary number of patients to be included. We hypothesized that sevoflurane will not affect cerebral $\mathrm{CO}_{2}$-reactivity at $1 \mathrm{MAC}$ (primary end point). Based on our previous study performed among non-anesthetized individuals, we found that hyperventilation lasting for $1 \mathrm{~min}$ results in a decrease of $\mathrm{PCO}_{2}$ by $7 \mathrm{mmhHg}$, accompanied by a $26.7 \mathrm{~cm} / \mathrm{s}$ decrease of the middle cerebral artery mean blood flow velocity [7]. Accordingly, we calculated that $1 \mathrm{mmHg}$ decrease of $\mathrm{PCO}_{2}$ results in a $3.84 \mathrm{~cm} / \mathrm{s}$ change in blood flow velocity. As per protocol we intended to decrease $\mathrm{CO}_{2}$ by $10 \mathrm{mmHg}$ in 2 steps, we calculated with a 38.4 $\mathrm{cm} / \mathrm{s}(30 \mathrm{~cm} / \mathrm{s}$ standard deviation) change, with a power of 0.9 and with an alpha of 0.01 . Our power calculation indicated that 12 patients need to be included to test our hypothesis. As both registration methods may be operator-dependent, for sake of clarity we decided to include 30 patients. The normality of distribution of data was tested by Shapiro-Wilks test. Thereafter, differences were analyzed with the Repeated Measures Analysis of Variance (ANOVA) with Bonferroni post hoc correction. Values of $p<0.05$ were accepted as statistically significant. Data are presented as mean (SD). MedCalc Statistical Software version 18.2.1. (MedCalc Software bvba, Ostend, Belgium) was used for statistical analy.

\section{Results}

\section{Demographic data}

Twenty-nine patients were enrolled aged 19-58 (mean 37), 17 female, 12 male. 7 patients underwent inguinal hiatal repair surgery, while 22 varicetomy. 1 patient was excluded due to inapproriate temporal window for TCD.

\section{Respiratory parameters and anesthetic depth during the procedure}

During the course of the study ventilatory settings were changed at different stages of the study to reach and maintain different levels of $\mathrm{EtCO}_{2}(40,35$ and $30 \mathrm{mmHg}$ respectively). Accordingly, there were significant differences in values of tidal volumes, respiratory rates. BIS values were stable during the entire procedure indicating adaequate depth of anesthesia (Table 1).

\section{Hemodynamic parameters}

There were no significant differences neither in systolic blood pressure values, nor in heart rate during the course of the study. In contrast, there were significant differences in diastolic blood pressure: preoperative 
Table 1 Hemodynamic parameters during the course of the study

\begin{tabular}{lllll}
\hline & $\mathrm{ETCO}_{2} 40$ & $\mathrm{ETCO}_{2} 35$ & $\mathrm{ETCO}_{2} 30$ & $p$ \\
\hline Tidal volume & $516(64)$ & $550(63)^{\ddagger \neq \neq}$ & $570(88)^{\ddagger \neq \neq}$ & $p<0.001$ \\
Respiratory rate & $9(2)^{\text {t+ }}$ & $12(13)^{\neq \neq \neq}$ & $15(3)^{\ddagger \neq \neq,+十 \dagger}$ & $p<0.001$ \\
BIS & $42(2)$ & $42(1)$ & $42(2)$ & $p=0.75$
\end{tabular}

Data are presented as mean (SD) *: Significant difference compared to preoperative values ${ }^{\ddagger}$ : Significant difference compared to $\mathrm{EtCO}_{2} 40$ values

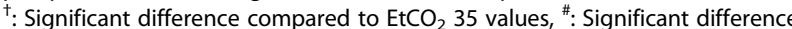

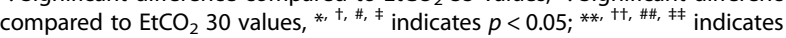
$p<0.01 ; * * *+t+\ldots \#, \ldots \neq \neq$ indicates $p<0.001$

values were significantly higher than values measured in any other timepoints (Table 2).

\section{Applanation tonometry parameters}

Mean arterial pressure significantly decreased during induction of anesthesia, reaching a steady state and remained stable during the entire course of the study. In parallel, aortic and peripheral pulse pressures both increased during the induction phase as did the augmentation index. All parameters remained unchanged during the next phases of the study (Fig. 2).

\section{Transcranial Doppler sonography parameters}

Preoperative middle cerebral artery mean blood flow velocity values were not significantly different from values measured at steady state sevoflurane stage under normocapnic conditions $\left(\mathrm{EtCO}_{2} 40 \mathrm{mmHg}\right)$. However, mean blood flow velocity values measured during $\mathrm{EtCO}_{2}$ 35 and $30 \mathrm{mmHg}$ were significantly different form each other as well as from preoperative and values measured at $\mathrm{EtCO}_{2} 40$ (Fig. 3). Pulsatility index values did not change during induction phase and reaching the steady state, however they significantly increased along with the decreased $\mathrm{EtCO}_{2}$ values (Fig. 4.). There was a strong significant correlation between $\mathrm{Vmean}$ and $\mathrm{EtCO}_{2}$ values $(p<0.001$, Pearson's $\mathrm{r}=0.79)$.

\section{Relationship between mean arterial pressure and cerebral blood flow velocity changes after induction and stabilisation of anesthesia}

We assessed the percent change between mean arterial pressure and middle cerebral artery mean blood flow velocity before anesthetic induction and $20 \mathrm{~min}$ after anesthesia was induced and a steady state of sevoflurane anesthesia was reached at normocapnic $\mathrm{PCO}_{2}(40 \mathrm{mmHg})$. As shown in Fig. 5, there was a significant linear relationship between the two parameters, indicating preserved static autoregulation of the cerebral circulation at normocapnic steady state of sevoflurane anesthesia.

\section{Discussion}

Anesthetic agents may have various effects on systemic circulation determining the cerebral perfusion pressure. Additionally, whyle using some agents, direct cerebral effect has also to be taken into account. Both effects are dose-dependent and are exerted through vasodilation or vasoconstriction of the cerebral vessels (medium-size vessels and arterioles), as well as through decreasing $\mathrm{CMRO}_{2}$ - thus influencing flow-metabolism coupling of the brain tissue. The main actors of this systemic and cerebral effects are cerebral arterioles, that are responsible for autoregulatory reactions during changes of cerebral blood flow and vasoreactivity related to metabolic changes [1]. Consequently, for sake of clarity, all the possible influencing factors (systemic and metabolic factors) have to be assessed in parallel while it is intended to test the effect of an anesthetic agent on cerebral blood flow, cerebral autoregulation and cerebral vasoreactivity. The proposed mechanisms of action of general anesthetics on cerebral circulation are summarized at Fig. 6.

Previous reports indicated that sevoflurane between 0.5-1.0 MAC has minimal direct vasodilatory effect on the brain arteries [8, 9] and has no systemic hemodynamic effects (cardiac contractility and/or peripheral vascular resistance) at the most frequently used $1 \mathrm{MAC}$ sevoflurane [10]. In the present study, during the induction phase, the combination of propofolfentanyl-rocuronium and adding sevoflurane resulted in a decreased mean arterial pressure (mainly due to the decrease of the diastolic pressure) and an increase in aortic and pulse pressure. During the later phases of anesthesia, however no significant changes occurred in any of the hemodynamic parameters (mean arterial pressure, aortic pressure, pulse pressure and augmentation index), indicating no systemic effects of sevoflurane. It is conceivable that the peripheral vasodilation oserved during the induction phase can be mainly ascribed to the use of propofol.

We found that reaching the stady state under sevoflurane anesthesia resulted in a decrease of the mean arterial pressure leading to non significant change in the

Table 2 Hemodynamic parameters during the course of the study

\begin{tabular}{llllll}
\hline & Preop & $\mathrm{ETCO}_{2} 40$ & $\mathrm{ETCO}_{2} 35$ & $\mathrm{ETCO}_{2} 30$ & $p$ \\
\hline Systolic blood pressure & $109(29)$ & $106(8)$ & $108(9)$ & $108(9)$ & $66(11)^{* * *}$ \\
Diastolic blood pressure & $81(9)$ & $65(10)^{* * *}$ & $67(10)^{* * *}$ & $6=0.46$ \\
Heart rate & $67(10)$ & $70(12)$ & $67(11)$ & $69(12)$ & $p=0.001$ \\
\hline
\end{tabular}

Data are presented as mean (SD), ${ }^{*}$ : Significant difference compared to preoperative measured values, ${ }^{* * *}$ indicates $p<0.001$ 

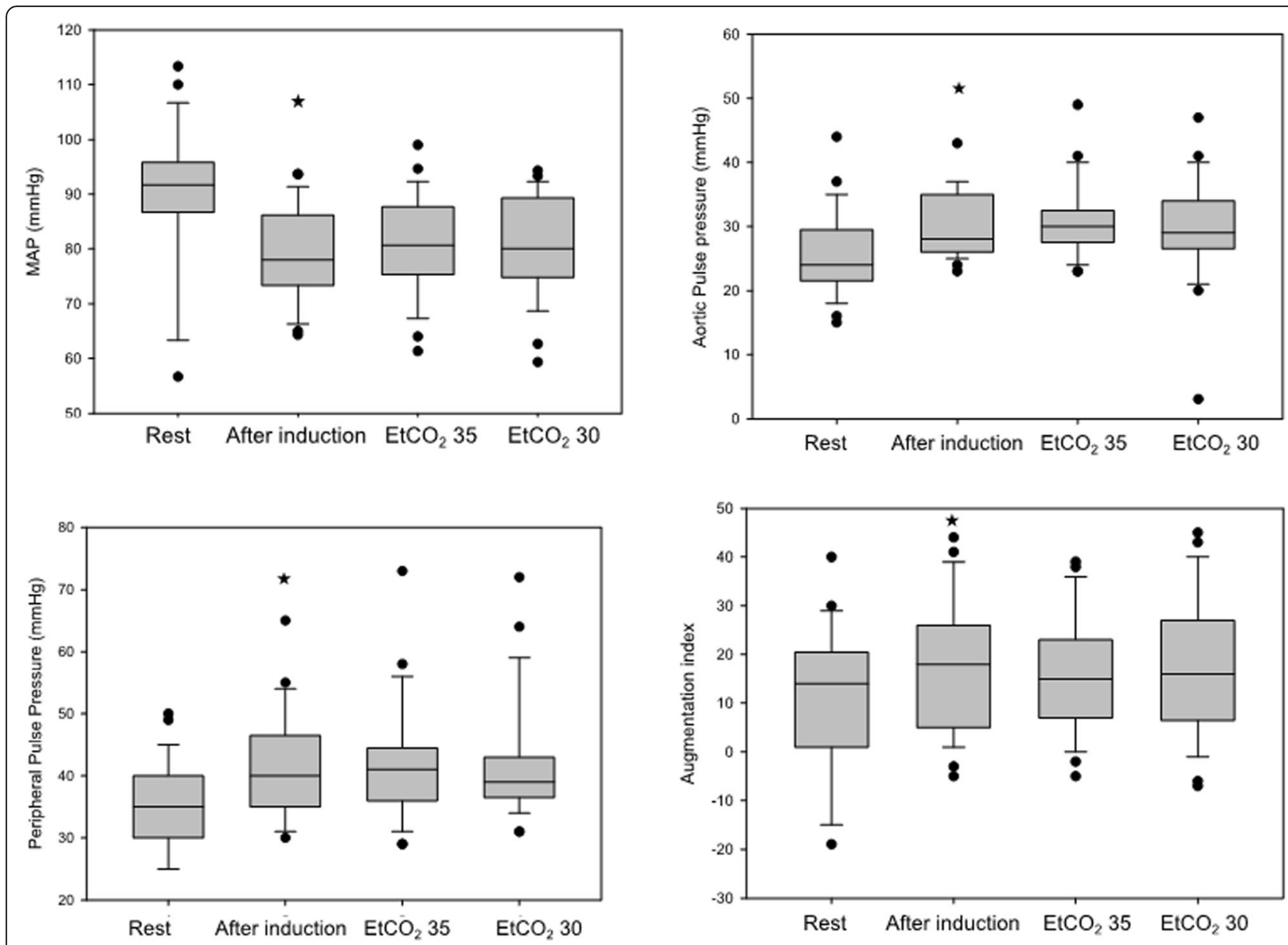

Fig. 2 Applanation tonometry parameters at rest and during the course of the study. Medians and $\mathrm{Cl}$ values are shown. ${ }^{*}$ indicates $p<0.05$ difference as compared to steady state values

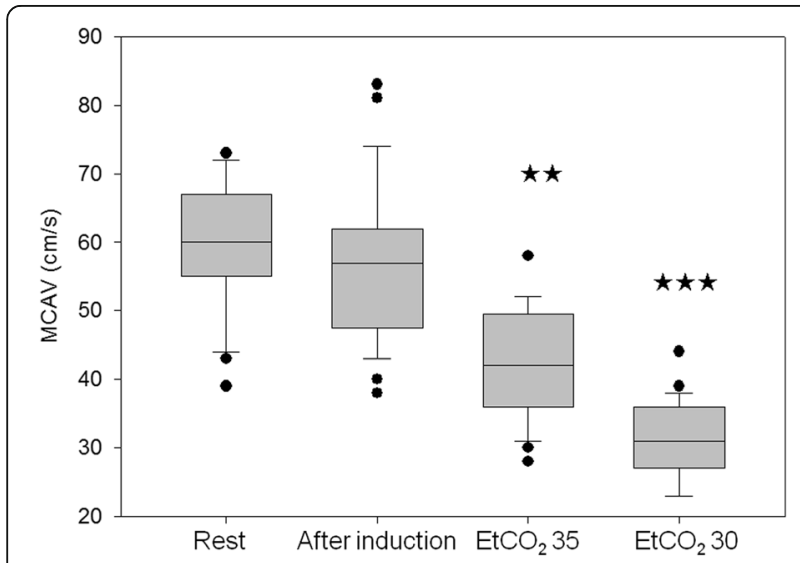

Fig. 3 Changes of middle cerebral artery mean blood flow velocity (MCAV) during the course of the study. Medians and $\mathrm{Cl}$ values are shown. ${ }^{* *}$ indicates $p<0.01,{ }^{* * *}$ indicates $p<0.001$ differences as compared to steady state values cerebral blood flow velocity. Cerebral autoregulation is defined as the inherent ability of the brain circulation to maintain a constant cerebral blood flow during changes of cerebral perfusion pressure [1]. In line with this, we checked the relationship between \%-changes of MAP and cerebral blood flow velocity values and found a linear relationship between the two factors, indicating preserved autoregulation. While mean arterial pressure decreased, cerebral blood flow velocity remained unchanged during the induction phase and reaching the steady state. As demonstrated in Fig. 5., pulsatility index (representing the vascular resistance of the cerebral arterioles) significantly decreased during this period enabling unchanged cerebral blood flow during the decrease of MAP.

Carbon-dioxide reactivity of the cerebral circulation is defined as the change in cerebral blood flow velocity per $\mathrm{mmHg}$ change in $\mathrm{PCO}_{2}$. In previous volunteer studies it has been demonstrated that forced hyperventilation lasting for $60 \mathrm{~s}$ results in a $38 \%$ percent decrease of the middle cerebral artery mean flood flow velocity 


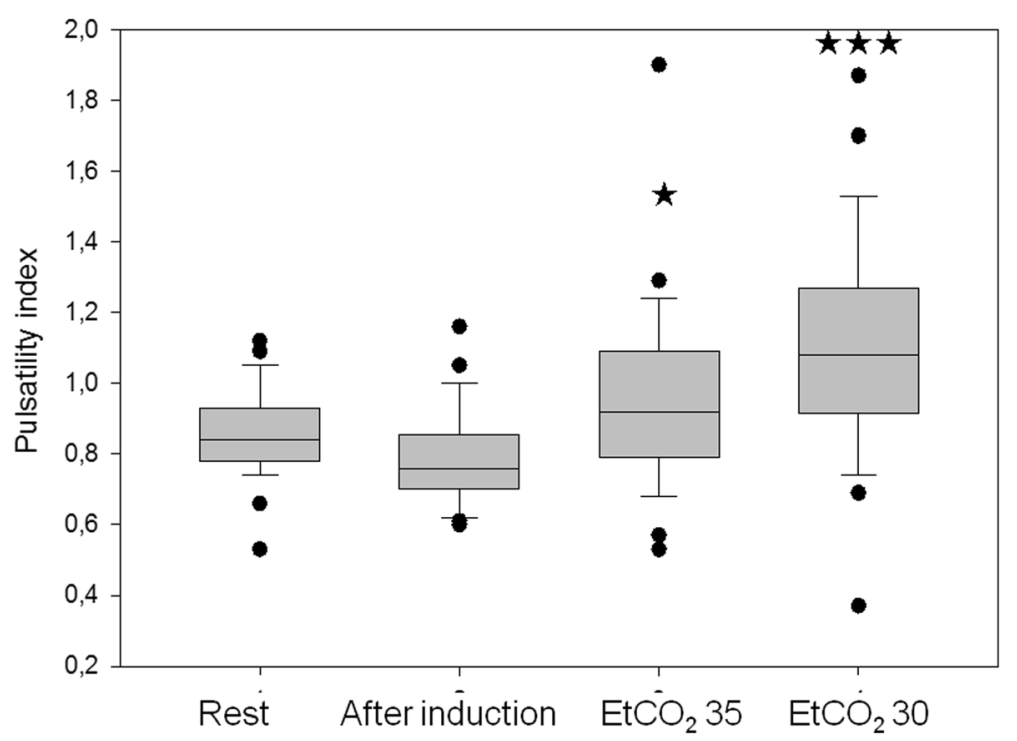

Fig. 4 Changes of pulsatility index during the course of the study. Medians and Cl values are shown. ${ }^{*}$ indicates $p<0.05$, ${ }^{* * *}$ indicates $p<0.001$ differences as compared to steady state values

compared to the resting BFV [7]. The accepted normal values for $\mathrm{CO}_{2}$-reactivity is $2-5 \mathrm{~cm} / \mathrm{s} / \mathrm{mmHg}$ [4]. In the present study a decrease of $\mathrm{PCO}_{2}$ from $40 \mathrm{mmHg}$ to 35 $\mathrm{mmHg}$ resulted in an average decrease of mean blood flow velocity of $4 \mathrm{~cm} / \mathrm{s} / \mathrm{mmHg}$, whereas to $30 \mathrm{mmgHg}$ $\mathrm{PCO}_{2}$ resulted in a decrease of $8 \mathrm{~cm} / \mathrm{s} / \mathrm{mmHg}$. These values correspond to the previous observations and indicate preserved $\mathrm{CO}_{2}$-reactivity during sevoflurane anesthesia at MAC 1 concentrations.
Both cerebral autoregulation and cerebral vasoreactivity are multifactorially determined defending mechanisms of the brain that aim to optimize global and cerebral circulation according to the actual metabolic needs. The main actors of these two mechanisms are cerebral arterioles, roughly $200 \mu \mathrm{m}$ in diameter [1]. The patency of autoregulatory and vasoreactivity reactions depends on systemic factors (such as cerebral perfusion pressure), local metabolic demands as well

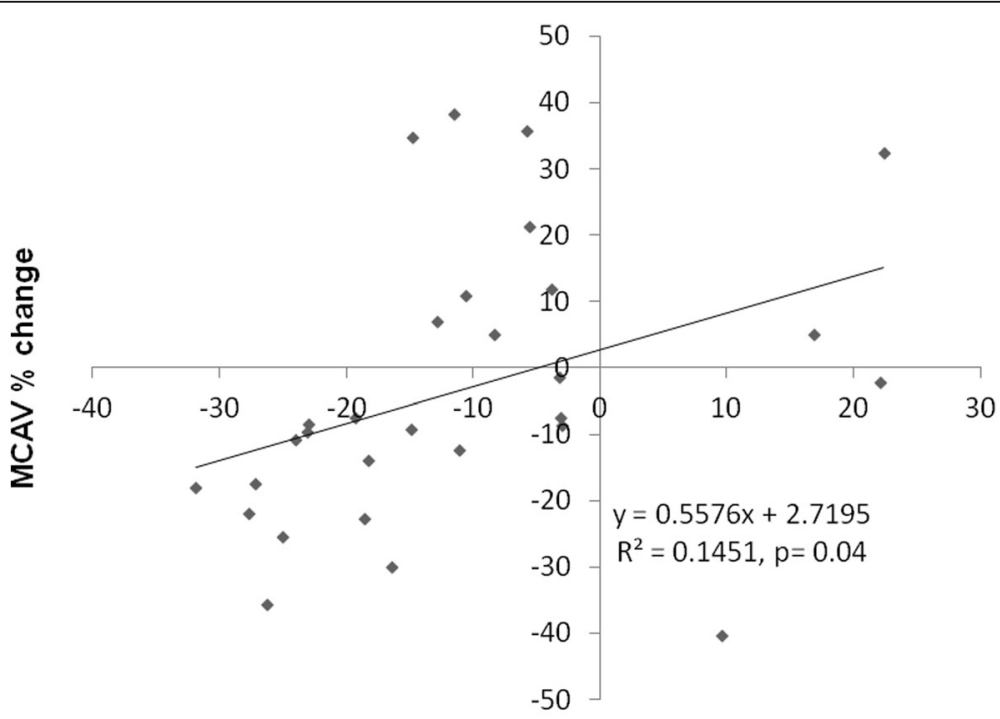

MAP $\%$ change

Fig. 5 Relationship between the \%change of mean arterial pressure (MAP) and middle cerebral artery mean blood flow velocity (MCAV) after anesthetic induction and reaching the steady state 


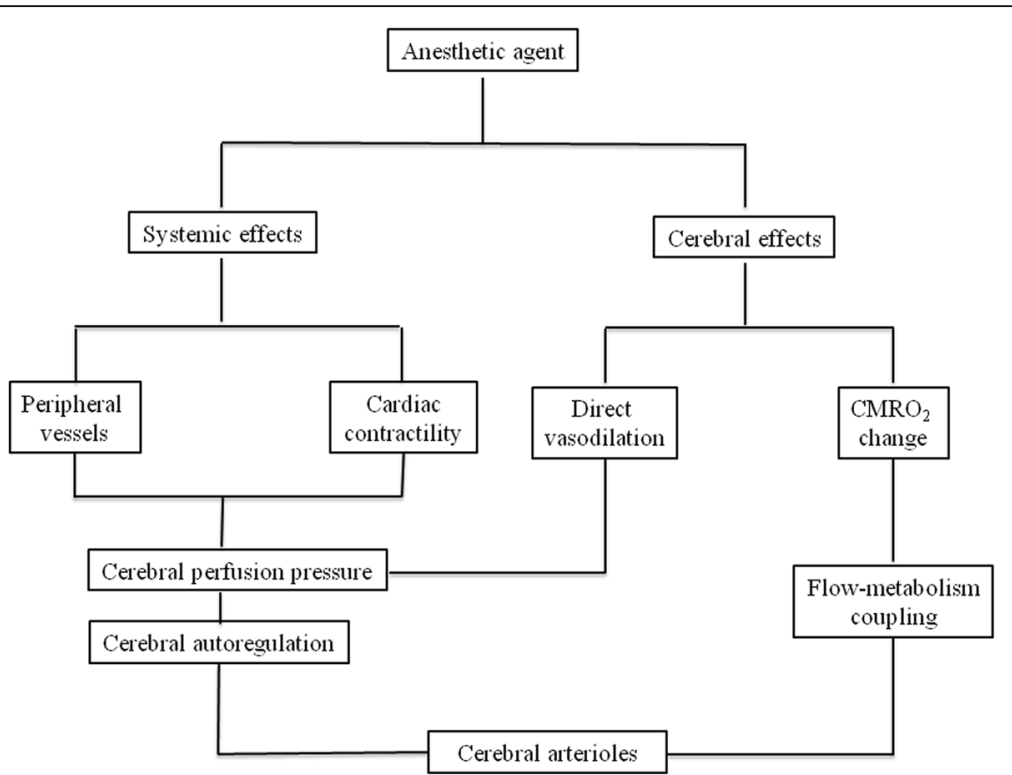

Fig. 6 The proposed mechanism of action of anesthetics on cerebral blood flow regulation

as underlying diseases of the patients. Previously it has been demonstrated that cerebral autoregulation and reactivity of the cerebral vessels to induced hypocapnia may be impaired in patients with certain underlying diseases, such as hypertension and diabetes mellitus [11-14]. As a consequence, sudden intraoperative changes of cerebral perfusion pressure and/or carbon-dioxide concentration may challenge the autoregulatory and metabolic regulatory responses and thus may result in critical brain tissue oxygenation. In line with our observations, previous studies in humans also demonstrated that sevoflurane at $\leq 1$ MAC concentrations does not affect cerebral autoregulation [15-17]. In a very recent study Sperna Weiland and co-workers found that sevoflurane does not affect the already impaired cerebral autoregulation in diabetic patients at clinicially applied doses [18].

Finally, we have to mention the limitations of our study. The methodological limitations are that transcranial Doppler does not measure cerebral blood flow, only changes of the blood flow velocities are proportional to cerebral blood flow values. Applanation tonometry that was used for monitoring the systemic hemodynamic effect is operator-dependent procedure. Therefore all measurements were performed by the same, experienced physician (DP). And finally, in the present study we only tested $\mathrm{CO}_{2}$-reactivity toward hypocapnic direction. This was done intentionally, as in the usual practice normocapnia is maintained during anesthesia and in specific neuroanesthetic cases only induced hypocapnia is used as the part of the intracranial pressure decreasing strategy.

\section{Conclusion}

Sevoflurane at clinically administered doses does not have any significant systemic hemodynamic effects and does not influence static cerebral autoregulation and cerebrovascular reactivity.

\section{Abbreviations}

CMRO2: Cerebral metabolic rate of oxygen; CO2: Carbon dioxide; EtCO2: End-tidal CO2; MAC: Minimum alveolar concentration; MAP: Mean arterial pressure

\section{Acknowledgements \\ None.}

\section{Authors' contributions}

$M J, L M, B F, D P, T V$ : performing intraoperative measurements, statistical analysis, drafting the manuscript, BF, CM: concept of the study, drafting the manuscript. All authors read and approved the final version of the manuscript.

\section{Funding}

The work was supported by the Hungarian Brain Research Program [grant number 2017-1.2.1-NKP-2017-00002], the founder is the Hungarian Academy of Sciences. Role: supporting central nervous system anesthesiology studies, $\mathrm{CM}, \mathrm{BF}$ are supported to design, perform and interpreting studies assessing the effect of anesthetics of cerebral blood flow.

\section{Availability of data and materials}

Data will be available upon request from the corresponding author.

\section{Ethics approval and consent to participate}

The study was approved by the local medical ethics committee of University of Debrecen, registration number: DEOEC RKEB/IKEB 3584-2012. All patients gave written consent to participate.

Consent for publication

Not applicable.

Competing interests

The authors declare that they have no competing interests. 


\section{Author details}

'Faculty of Medicine, Department of Anesthesiology and Intensive Care, University of Debrecen, Nagyerdei krt. 98, Debrecen, Hungary. ${ }^{2}$ Faculty of Medicine, Department of Medicine, University of Debrecen, Debrecen, Hungary. ${ }^{3}$ Hungarian Center, Outcomes Research Consortium, Cleveland, USA.

Received: 21 March 2019 Accepted: 11 June 2019

\section{Published online: 19 June 2019}

\section{References}

1. Settakis G, Molnár C, Kerényi L, Kollár J, Legemate D, Csiba L, Fülesdi B. Acetazolamide as a vasodilatory stimulus in cerebrovascular diseases and in conditions affecting the cerebral vasculature. Eur J Neurol. 2003;10(6):609-20.

2. Nishiyama T, Matsukawa T, Yokoyama T, Hanaoka K. Cerebrovascular carbon dioxide reactivity during general anesthesia: a comparison between sevoflurane and isoflurane. Anesth Analg. 1999:89:1437-41.

3. Dagal A, Lam AM. Cerebral autoregulation and anesthesia. Curr Opin Anaesthesiol. 2009:22:547-52.

4. Mariappan R, Mehta J, Chui J, Manninen P, Venkatraghavan L. Cerebrovascular reactivity to carbon dioxide under anesthesia: a qualitative systematic review. J Neurosurg Anesthesiol. 2015;27(2):123-35.

5. Goettel N, Patet C, Rossi A, Burkhart CS, Czosnyka M, Strebel SP, Steiner LA. Monitoring of cerebral blood flow autoregulation in adults undergoing sevoflurane anesthesia: a prospective cohort study of two age groups. J Clin Monit Comput. 2016:30:255-64.

6. Sárkány P, Lengyel S, Nemes R, Orosz L, Páll D, Molnár C, Fülesdi B. Noninvasive pulse wave analysis for monitoring the cardiovascular effects of CO2 pneumoperitoneum during laparoscopic cholecystectomy--a prospective case-series study. BMC Anesthesiol. 2014;14:98.

7. Settakis G, Lengyel A, Molnár C, Bereczki D, Csiba L, Fülesdi B. Transcranial Doppler study of the cerebral hemodynamic changes during breathholding and hyperventilation tests. J Neuroimaging. 2002;12:252-8.

8. Kadoi Y, Takahashi K, Saito S, Goto F. The comparative effects of sevoflurane versus isoflurane on cerebrovascular carbon dioxide reactivity in patients with diabetes mellitus. Anesth Analg. 2006;103:168-72.

9. Matta BF, Heath KJ, Tipping K, Summors AC. Direct cerebral vasodilatory effects of sevoflurane and isoflurane. Anesthesiology. 1999;91:677-80.

10. Ebert TJ, Harkin CP, Muzi M. Cardiovascular responses to sevoflurane: a review. Anesth Analg. 1995;81(6 Suppl):S11-22.

11. Fülesdi B, Limburg M, Bereczki D, Michels RP, Neuwirth $G$, Legemate $D$, Valikovics A, Csiba L. Impairment of cerebrovascular reactivity in long-term type 1 diabetes. Diabetes. 1997:46:1840-5.

12. Páll D, Lengyel S, Komonyi E, Molnár C, Paragh G, Fülesdi B, Katona E. Impaired cerebral vasoreactivity in white coat hypertensive adolescents. Eur J Neurol. 2011;18:584-9.

13. Settakis G, Páll D, Molnár C, Bereczki D, Csiba L, Fülesdi B. Cerebrovascular reactivity in hypertensive and healthy adolescents: TCD with vasodilatory challenge. J Neuroimaging. 2003;13:106-12.

14. Siró P, Molnár C, Katona É, Antek C, Kollár J, Settakis G, Fülesdi B. Carotid intima-media thickness and cerebrovascular reactivity in long-term type 1 diabetes mellitus. J Clin Ultrasound. 2009:37:451-6.

15. Molnár C, Settakis G, Sárkány P, Kálmán S, Szabó S, Fülesdi B. Effect of sevoflurane on cerebral blood flow and cerebrovascular resistance at surgical level of anaesthesia: a transcranial Doppler study. Eur J Anaesthesiol. 2007;24:179-84

16. Gupta S, Heath K, Matta BF. Effect of incremental doses of sevoflurane on cerebral pressure autoregulation in humans. Br J Anaesth. 1997;79:469-72.

17. Summors AC, Gupta AK, Matta BF. Dynamic cerebral autoreg ulation during sevoflurane anesthesia: a comparison with isoflurane. Anesth Analg. 1999:88:341-5.

18. Sperna Weiland NH, Hermanides J, van der Ster BJP, Hollmann MW, Preckel B, Stok WJ, van Lieshout JJ, Immink RV. Sevoflurane based anaesthesia does not affect already impaired cerebral autoregulation in patients with type 2 diabetes mellitus. Br J Anaesth. 2018;121:1298-307.

\section{Publisher's Note}

Springer Nature remains neutral with regard to jurisdictional claims in published maps and institutional affiliations.

\section{Ready to submit your research? Choose BMC and benefit from:}

- fast, convenient online submission

- thorough peer review by experienced researchers in your field

- rapid publication on acceptance

- support for research data, including large and complex data types

- gold Open Access which fosters wider collaboration and increased citations

- maximum visibility for your research: over $100 \mathrm{M}$ website views per year

At $\mathrm{BMC}$, research is always in progress.

Learn more biomedcentral.com/submissions 